\title{
Correction to: Broken promises: a rights-based analysis of marginalised livelihoods and experiences of food insecurity in large-scale land investments in Tanzania
}

\author{
Atenchong Talleh Nkobou ${ }^{1}$ (D) Andrew Ainslie ${ }^{1} \cdot$ Stefanie Lemke ${ }^{2,3}$ \\ Published online: 18 October 2021 \\ (c) International Society for Plant Pathology and Springer Nature B.V. 2021
}

Correction to: Food Security

https://doi.org/10.1007/s12571-021-01195-3

The original version of this article unfortunately contained mistakes introduced during the production process.

The Acknowledgements and Author's contribution sections were missing from this article and should have read as follows:

Acknowledgements Special thanks go to MVIWATA Ruvuma, Tanzania for providing infrastructure and assistance to conduct this research, and Maria Daniela Núñez Burbano de Lara for her contributions to initial ideas on the conceptual framework and previous research which formed the basis for this study. We further extend our gratitude to Kerstin Lanje, Denis Mpagaze, Frank Ademba, Prof. Chris Maina Peter, Magdalena Lugu, Joshua Mlewa and Prof. Rosa Freedman. We are

grateful for the helpful comments of two anonymous reviewers, which helped to improve this paper further. Financial support from the Commonwealth Scholarship Commission is greatly acknowledged.

Author's contribution Atenchong Talleh Nkobou and Stefanie Lemke conceptualised and designed the study and methodological approach applied in this research, with contributions from Andrew Ainslie. Data collection and analysis were performed by ATN, with input from Stefanie Lemke and Andrew Ainslie. The manuscript was written by Atenchong Talleh Nkobou and Stefanie Lemke, with contributions on an earlier version of the paper and final review by Andrew Ainslie. All authors read and approved the final manuscript.

The original article has been corrected.

Publisher's Note Springer Nature remains neutral with regard to jurisdictional claims in published maps and institutional affiliations.

The original article can be found online at https://doi.org/10.1007/ s12571-021-01195-3.

Atenchong Talleh Nkobou

atenchongtallehnkobou@pgr.reading.ac.uk

Andrew Ainslie

a.m.ainslie@ reading.ac.uk

Stefanie Lemke

stefanie.lemke@boku.ac.at

1 School of Agriculture, Policy and Development, University of Reading, Reading, UK

2 Institute for Development Research, University of Natural Resources and Life Sciences (BOKU), Vienna, Austria

3 Centre for Agroecology, Water and Resilience (CAWR), Coventry University, Coventry, UK 